\title{
Production of Biopolyamide
} Precursors 5-Amino Valeric Acid and Putrescine From Rice Straw Hydrolysate by Engineered Corynebacterium glutamicum

\author{
Keerthi Sasikumar1,2, Silvin Hannibal ${ }^{3}$, Volker F. Wendisch ${ }^{3}$ and \\ K. Madhavan Nampoothiri1,2*
}

${ }^{1}$ Microbial Processes and Technology Division (MPTD), CSIR-National Institute for Interdisciplinary Science and Technology, Thiruvananthapuram, India, ${ }^{2}$ Academy of Scientific and Innovative Research (AcSIR), Ghaziabad, India, ${ }^{3}$ Genetics of

Prokaryotes, Faculty of Biology \& CeBiTec, Bielefeld University, Bielefeld, Germany

\section{OPEN ACCESS}

Edited by:

Evangelos Topakas,

National Technical University

of Athens, Greece

Reviewed by:

Gerd M. Seibold,

Technical University of Denmark,

Denmark

Fengjie Cui,

Jiangsu University, China

*Correspondence:

K. Madhavan Nampoothiri madhavan@niist.res.in;

madhavan85@hotmail.com

Specialty section:

This article was submitted to

Industrial Biotechnology,

a section of the journal

Frontiers in Bioengineering and

Biotechnology

Received: 30 November 2020

Accepted: 09 March 2021

Published: 29 March 2021

Citation:

Sasikumar K, Hannibal S, Wendisch VF and Nampoothiri KM (2021) Production of Biopolyamide

Precursors 5-Amino Valeric Acid and Putrescine From Rice Straw

Hydrolysate by Engineered

Corynebacterium glutamicum

Front. Bioeng. Biotechnol. 9:635509.

doi: 10.3389/fbioe.2021.635509
The non-proteinogenic amino acid 5-amino valeric acid (5-AVA) and the diamine putrescine are potential building blocks in the bio-polyamide industry. The production of 5-AVA and putrescine using engineered Corynebacterium glutamicum by the coconsumption of biomass-derived sugars is an attractive strategy and an alternative to their petrochemical synthesis. In our previous work, 5-AVA production from pure xylose by C. glutamicum was shown by heterologously expressing xylA from Xanthomonas campestris and $x y / B$ from C. glutamicum. Apart from this AVA Xyl culture, the heterologous expression of $x y \mid A_{X_{C}}$ and $x y \mid B_{C g}$ was also carried out in a putrescine producing C. glutamicum to engineer a PUT Xyl strain. Even though, the pure glucose (40 $\mathrm{g} \mathrm{L}^{-1}$ ) gave the maximum product yield by both the strains, the utilization of varying combinations of pure xylose and glucose by AVA XYl and PUT XYl in CGXII synthetic medium was initially validated. A blend of $25 \mathrm{~g} \mathrm{~L}^{-1}$ of glucose and $15 \mathrm{~g} \mathrm{~L}^{-1}$ of xylose in CGXII medium yielded $109 \pm 2 \mathrm{mg} \mathrm{L}^{-1}$ putrescine and $874 \pm 1 \mathrm{mg} \mathrm{L}^{-1} 5$-AVA after $72 \mathrm{~h}$ of fermentation. Subsequently, to demonstrate the utilization of biomass-derived sugars, the alkali $(\mathrm{NaOH})$ pretreated-enzyme hydrolyzed rice straw containing a mixture of glucose (23.7 $\mathrm{g} \mathrm{L}^{-1}$ ) and xylose (13.6 $\mathrm{g} \mathrm{L}^{-1}$ ) was fermented by PUT Xyl and AVA Xyl to yield $91 \pm 3 \mathrm{mg} \mathrm{L}^{-1}$ putrescine and $260 \pm 2 \mathrm{mg} \mathrm{L}^{-1} 5$-AVA, respectively, after $72 \mathrm{~h}$ of fermentation. To the best of our knowledge, this is the first proof of concept report on the production of 5-AVA and putrescine using rice straw hydrolysate ( $\mathrm{RSH}$ ) as the raw material.

Keywords: 5-amino valeric acid, Corynebacterium glutamicum, polyamides, putrescine, rice straw hydrolysate

\section{INTRODUCTION}

The severe global environmental impact of the polyamide industries demands an alternative process to their current synthesis from the petrochemical routes. As the demand for these commercially relevant conventional plastics increases tremendously day by day, a new green approach for their sustainable production from renewable sources, with biodegradability and biocompatibility owes a competitive advantage and could be the most significant replacement for the current scenario. 
Polyamides are homopolymers of terminal amino acids or co-polymers of diacids and diamines. The non-ribosomal amino acid 5-AVA is a glutaric acid derivative, an important precursor and an attractive building block for the synthesis of the polyamides. Apart from considering the importance of this five-carbon non-proteinogenic amino acid, as a potential monomer for the synthesis of nylon 5 and nylon 65 (Pukin et al., 2010; Adkins et al., 2013), their biotechnological production also gains considerable interest. A global high-performance polyamide market size report (Grand View Research Inc, 2020) projects a Compound annual growth rate (CAGR) of $7.1 \%$ for the high-performance polyamides from 2020 to 2027 as their consumption is highly increased for the production of insulation materials, industrial brushes and medical, healthcare products. 5-AVA is naturally produced as an intermediate by Pseudomonas putida in the degradation of L-lysine by AMV pathway (Liu et al., 2014), whereas, in Pseudomonas aeruginosa 5-AVA is produced by the transamination and oxidation of cadaverine, which in turn is produced by the decarboxylation of lysine (Jae et al., 2013). Successful metabolic engineering approaches have been established in E. coli and Corynebacterium strains for the production of 5-AVA from glucose, by the expression of L-lysine monoxygenase (DavB) and 5-amino valeramide amidohydrolase (DavA) genes of Pseudomonas putida (Cho et al., 2016). The four-carbon diamine-putrescine called 1,4-diaminobutane is a low molecular weight nitrogenous base and an essential monomer used in the chemical industry for the synthesis of effective bioplastic nylon-4,6 with a high melting point and exceptional chemical resistance. A metabolically engineered E. coli K12 W3110 was reported to produce putrescine from glucose minimal medium (Qian et al., 2009). The requirement for putrescine is estimated to be about 10,000 tons per year in Europe and this demand is expected to drastically increase in the coming years. Schneider et al. (2012) have reported a stable putrescine production from glucose with $C$. glutamicum by modifying the OTC activity and by expressing ornithine decarboxylase gene speC from E. coli.

The soil-dwelling Gram-positive bacterium Corynebacterium glutamicum has a very well-developed genetic toolbox and has been extensively explored by metabolic engineering, for decades for the effectual industrial production of amino acids such as lysine. Many value-added compounds like the $\mathrm{N}$-methylated amino acids, sarcosine (Mindt et al., 2019), 7-choro tryptophan (Veldmann et al., 2019) and several intermediate precursors of amino acids, for example, 2oxovalerate (Krause et al., 2010) and pyruvate (Wieschalka et al., 2012) have been successfully produced by the recombinant C. glutamicum strains. Several researchers across the globe have been studying the possibilities of ethanol production from the agro-residues for decades as these commodities are cheaply available in large quantities (Duff and Murray, 1996; Binod et al., 2010; Oberoi et al., 2010, 2012; Sarkar et al., 2012). The major agro-residual biomass includes rice straw, wheat straw, corn straw, cottonseed hair, seaweed, paper, pineapple leaf, banana stem, jatropha waste, and sugarcane bagasse (Kim and Dale, 2004).
Rice straw is one of the most abundant and underutilized agricultural wastes, rich in the structural carbohydratescellulose (32-47 \%) and hemicellulose (19-27\%), densely packed in lignin (5-24\%) (Mosier et al., 2005; Kawaguchi et al., 2006). Cellulose is composed of repeating units of cellobiose and hemicellulose consists of several sugars like D-glucose, D-mannose, D-galactose, D-xylose, arabinose, and rhamnose. The depolymerization of rice straw into fermentable sugars turns it into a preferable primary carbon source for the microbial biocatalysts and biotransformation to commercially significant high-performance compounds making it an alternative to the pure sugar monomers like glucose, which have competing uses in the food industries (Jorge et al., 2016). The pretreatment of rice straw results in the formation of several compounds like furfural, hydroxyl methyl furfural, and 4-hydroxybenzaldehyde which inhibit the growth of many bacteria but C. glutamicum has been shown to withstand the pretreatment derived inhibitors (Gopinath et al., 2011). The wild type C. glutamicum ATCC 31831 utilize arabinose (Sasaki et al., 2009), whereas C. glutamicum ATCC 13032 consumes the pentose ribose (Wendisch, 2003; Rey et al., 2005) but cannot utilize xylose (Kawaguchi et al., 2006). C. glutamicum has been successfully engineered to consume xylose for growth and production. The scarcity of pentose utilizing microorganisms is a drawback for the successful industrial application of bioprocesses for the synthesis of economically important platform chemicals from lignocellulosic biomass. This study dealt with the exploitation of rice straw, a locally available surplus lignocellulosic biomass, as an alternative renewable raw material for the production of high-value products such as 5-AVA and putrescine by the simultaneous utilization of glucose and xylose, the abundant pentose sugar in biomass by employing the metabolically engineered C. glutamicum strains.

\section{MATERIALS AND METHODS}

\section{Bacterial Strains and Culture Conditions}

Bacterial strains and plasmids used in this work are listed in Table 1. Escherichia coli DH5a containing the pECXT99A$x y l A_{X c} x y l B_{C g}$ plasmid (Jorge et al., 2017b) was used for extracting plasmid DNA. E. coli and C. glutamicum cells were cultivated in lysogeny broth (LB) medium $\left(10 \mathrm{~g} \mathrm{~L}^{-1}\right.$ of tryptone, $5 \mathrm{~g} \mathrm{~L}^{-1}$ yeast extract, and $10 \mathrm{~g} \mathrm{~L}^{-1}$ sodium chloride) or brain-heartinfusion (BHI) broth in $100 \mathrm{~mL}$ baffled flasks at $120 \mathrm{rpm}$ at $37^{\circ} \mathrm{C}$ or $30^{\circ} \mathrm{C}$, respectively. Kanamycin $\left(25 \mu \mathrm{g} \mathrm{mL}^{-1}\right)$, tetracycline (5 $\left.\mu \mathrm{g} \mathrm{mL} L^{-1}\right)$, spectinomycin $(100 \mu \mathrm{g} \mathrm{mL}-1)$, and $1 \mathrm{mM}$ isopropyl $\beta$-D-1-thiogalactopyranoside (IPTG) were added when necessary. The pre-cultures of C. glutamicum AVA Xyl and PUT Xyl were grown in brain-heart-infusion (BHI) broth and incubated at $30^{\circ} \mathrm{C}$ and $200 \mathrm{rpm}$. For fermentation experiments, C. glutamicum strains were grown in CGXII basal medium with desired sugar concentrations and antibiotics, incubated at $30^{\circ} \mathrm{C}$, in a rotary shaker $(200 \mathrm{rpm})$. For all the fermentation experiments, the seed cultures were inoculated from fresh $\mathrm{BHI}$ agar plates containing appropriate antibiotics and a final concentration of $1 \mathrm{mM}$ isopropyl- $\beta$-D-thiogalactopyranoside (IPTG) was added at the time of inoculation. The bacterial strains 
TABLE 1 | Strains and plasmids used in this study.

\begin{tabular}{|c|c|c|}
\hline $\begin{array}{l}\text { Strains and } \\
\text { plasmids }\end{array}$ & Characteristics & References \\
\hline \multicolumn{3}{|l|}{ Strains } \\
\hline $\begin{array}{l}\text { C. glutamicum } \\
\text { NA6 }\end{array}$ & $\begin{array}{l}\text { Putrescine producer strain; C. glutamicum } \\
\text { ATCC13032 } \\
\text { odhA }{ }^{T T G} \text { odhl }{ }^{T 15 A} \Delta \text { argF } \Delta \text { argR } \Delta \text { snaA, carrying } \\
\text { IPTG-inducible pWWEx1-speC-gapA-pyc- } \\
\arg ^{B A 49 V / M 54 V} \text {-argF } F_{21}\end{array}$ & $\begin{array}{l}\text { Nguyen et al., } \\
2015\end{array}$ \\
\hline $\begin{array}{l}\text { C. glutamicum } \\
\text { PUT Xyl }\end{array}$ & $\begin{array}{l}\text { Putrescine producer strain growing on xylose; } \\
\text { C. glutamicum NA6 derivative, carrying } \\
\text { IPTG-inducible plasmid } \\
\text { pECXT99A-xyIA } A_{X C} x y / B_{C g}\end{array}$ & This work \\
\hline $\begin{array}{l}\text { C. glutamicum } \\
\text { AVA Xyl }\end{array}$ & $\begin{array}{l}\text { 5-Aminovalerate producer strain growing on } \\
\text { xylose; C. glutamicum 5AVA3 } \\
\left(\text { pECXT99A-xylA } x_{C} x y \mid B_{C g}\right)= \\
\text { GRLys1 } \Delta \text { sugR } \Delta / d h A \Delta s n a A \Delta c g m A \Delta g a b T D P \\
\text { derivative carrying IPTG-inducible plasmids } \\
\text { pWWEx1-IdcC, pEKEx3-patDA, and } \\
\text { pECXT99A-xylA } x_{C} x y I B C g\end{array}$ & $\begin{array}{l}\text { Jorge et al., } \\
2017 b\end{array}$ \\
\hline $\begin{array}{l}\text { E. coli DH5 } \alpha \\
\text { (pECXT99A- } \\
\left.x y / A_{x c} x y / B_{C g}\right)\end{array}$ & $\begin{array}{l}\text { E. coli DH5 } \alpha \text { strain carrying IPTG-inducible } \\
\text { plasmid pECXT99A-xyIA }{ }_{X_{C} \times y / B_{C g}}\end{array}$ & $\begin{array}{l}\text { Jorge et al., } \\
2017 \mathrm{~b}\end{array}$ \\
\hline \multicolumn{3}{|l|}{ Plasmids } \\
\hline $\begin{array}{l}\text { pECXT99A- } \\
x y\left|A_{x_{C}} x y\right| B_{C g}\end{array}$ & $\begin{array}{l}\text { pECXT99A-derived (Kirchner and Tauch, 2003), } \\
\text { IPTG-inducible vector for the simultaneous } \\
\text { overexpression of xylA from Xanthomonas } \\
\text { campestris SCC1758 and xyIB from C. } \\
\text { glutamicum ATCC13032 }\end{array}$ & $\begin{array}{l}\text { Jorge et al., } \\
2017 \mathrm{~b}\end{array}$ \\
\hline
\end{tabular}

were preserved in $40 \%$ glycerol at $80^{\circ} \mathrm{C}$ for long-term storage and maintained $\mathrm{BHI}$ agar plates supplemented with necessary antibiotics and preserved at $4^{\circ} \mathrm{C}$ for the short term.

\section{Genetic Manipulations}

C. glutamicum competent cells were prepared as described by Jorge et al. (2017a). Competent cells were transformed by electroporation (Eggeling and Bott, 2005) at $25 \mu \mathrm{F}, 200 \Omega$, and $2.5 \mathrm{kV}$ using plasmid DNA extracted from $E$. coli DH5 $\alpha$ cells. Plasmid DNA extraction was performed with a GeneJET $^{\text {TM }}$ Plasmid Miniprep Kit (Thermo Fisher Scientific, MA, United States) following the manufacturer's information.

\section{Molecular Design and Genetic Engineering of C. glutamicum PUT Xyl and AVA Xyl}

The C. glutamicum ATCC13032 derived strain NA6 (Nguyen et al., 2015) used for the construction of xylose-utilizing Put Xyl (see Figure 1A) carries several modifications for putrescine production, including modifications for the improvement of 2-oxoglutarate supply (overexpression of gapA and $p y c$, and reduced 2-oxoglutarate dehydrogenase activity due to odh $A^{\text {TTG }}$ and $\left.o d h I^{T 15 A}\right)$, for the de-repression of the arginine biosynthesis by chromosomal deletion of $\operatorname{argR}$, for the overexpression of a feedback-resistant $\mathrm{N}$-acetyl glutamate kinase $\left(\arg B^{A 49 V / M 54 V}\right)$, as well as for the prevention of by-product formation by the chromosomal deletions of $\operatorname{argF}$ and snaA. To avoid costly arginine supplementation due to the resulting arginine auxotrophy, a plasmid addiction system was created by inserting the $\arg F_{21}$ gene variant (Schneider et al., 2012), which encodes an ornithine transcarbamoylase with reduced activity, into the pVWEx1-derived (Peters-Wendisch et al., 2001) expression vector (Nguyen et al., 2015).

C. glutamicum, harboring xylulose kinase $x y l B$ but lacking xylose isomerase $x y l A$ for the first conversion step of the xylose isomerase pathway, is not capable of metabolizing xylose naturally. In this work, the NA6 strain (Nguyen et al., 2015) was transformed with the ITPG-inducible pECXT99A- $x y l A_{X c} x y l B_{C g}$ vector (Jorge et al., 2017b) for the overexpression of the xylose isomerase pathway, containing xylA from Xanthomonas campestris SCC1758 and $x y l B$ from C. glutamicum ATCC13032.

The corresponding 5-aminovalerate producer strain 5-AVA3 (pECXT99A- $x y l A_{X c} x y l B_{C g}$ ) already constructed in the previous work of Jorge et al. (2017b) was renamed to AVA Xyl (see Figure 1B) in this study. 5-AVA3 is a derivative of the genome-reduced lysine producer strain GRLys1 (Unthan et al., 2015), which lacks three genomic prophage regions and the phosphoenolpyruvate carboxykinase gene $p c k$. Introduction of point mutations into the genes $l y s C$, $p y c$, and hom, and chromosomal duplication of the lysine pathway genes lys $C$, asd, $d a p A, d a p B, d d h, l y s A$, and $l y s E$ resulted in an effective lysine producer strain. For the construction of the production strain 5AVA3 (Jorge et al., 2017b) deleted the transcriptional regulator of the sugar metabolism sugR to improve the glucose uptake, ldhA, snaA, cgmA, and gabTDP to prevent the side-product formation of lactate, $\mathrm{N}$-acetyl cadaverine, cadaverine, as well as glutarate, and introduced the expression vectors pVWEx1-ldcC and pEKEx3-patDA to establish 5-AVA formation from lysine.

Supplementary Figure 1 shows the agarose gel of PCR fragments to verify the transformation of $C$. glutamicum NA6 with pECXT99A- $x y l A_{X c} B_{C g}$ vector (expected fragment size: 3,312 bp) and Supplementary Table 1 shows the pECXT99A primers used.

\section{Quantification of Sugars and Amines in the Fermented Broth}

The sugars and amines in the fermentation broth were analyzed by RP-HPLC. The quantification of sugars was performed on a Shimadzu UFLC system LC-20AT Prominance Liquid Chromatograph equipped with a Refractive Index Detector (Shimadzu RID-10A), an autosampler (SIL 20AC HT) and a Column oven (CTO-20ACV) operated at $80^{\circ}$ C. Shimadzu Lab Solutions data management software was used. The monomeric sugars (xylose and glucose) were resolved using Rezex RPM $\mathrm{Pb}^{+}$cation exchange monosaccharide column $(300 \times 7.5 \mathrm{~mm}$, Phenomenex) with Milli Q water (Millipore) at a $0.60 \mathrm{~mL} / \mathrm{min}$ isocratic flow rate and a $10 \mu \mathrm{L}$ sample injection volume. Putrescine and 5-AVA were quantified using a Shimadzu UFLC system equipped with a fluorescence detector (RF 20A) at excitation and emission wavelengths of 348 and $450 \mathrm{~nm}$, respectively. The samples were filtered through $0.22 \mu \mathrm{m}$ filter membranes (PALL Lifesciences), buffered at a $\mathrm{pH} 10$ using borate buffer (Agilent) and pre-derivatized with o-phthaldialdehyde 

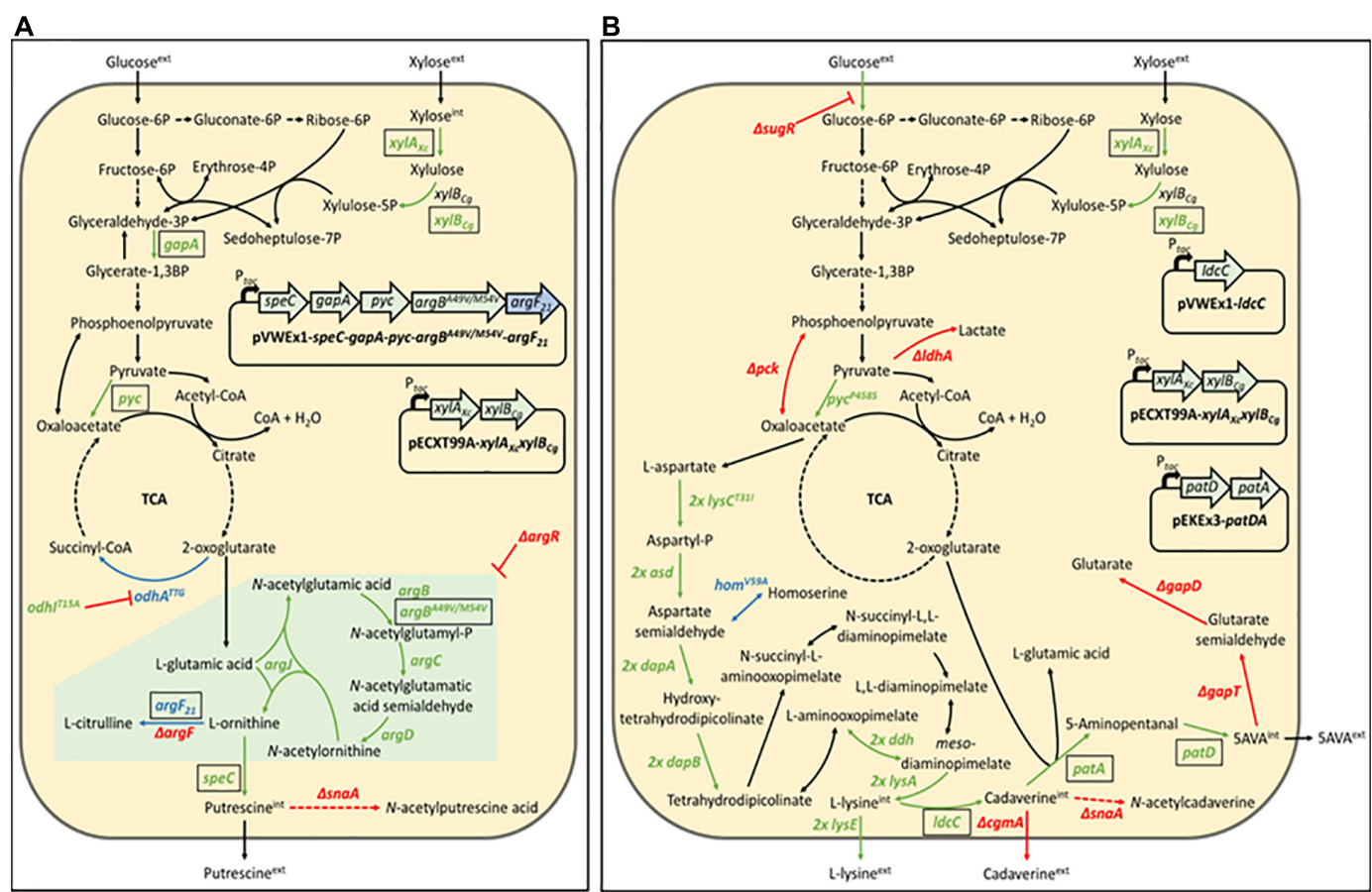

FIGURE 1 | Schematic representation of the putrescine production route in Corynebacterium g/utamicum PUT Xyl (A) and the 5-aminovalerate production route in C. glutamicum AVA Xyl (B). Gene names of key enzymes are given next to the corresponding reaction (pointed arrows). Black-boxed gene names indicate plasmid-borne expression, unboxed gene names indicate genomic expression. Reaction routes involving more than one gene are depicted by dashed arrows. Repression is represented by blunt arrows. Upregulated reactions are shown in green, downregulated reactions are shown in blue, and deleted reactions are shown in red. The green-boxed arginine pathway in (A) indicate upregulation by deletion of the repressor of the arginine biosynthesis $\mathbf{A r g} \boldsymbol{R}$. $\arg \mathbf{B}^{\mathbf{A 4 9 V} / \mathbf{M 5 4 V}}$,

feedback-resistant $\mathrm{N}$-acetyl glutamate kinase; $\boldsymbol{a r g} \boldsymbol{F}$, ornithine transcarbamoylase; $\boldsymbol{a r g} \boldsymbol{F}_{\mathbf{2} 1}$, ornithine transcarbamoylase with reduced activity; $\boldsymbol{a r g} \boldsymbol{R}$, repressor of the arginine biosynthesis; asd (2 copies), aspartate-semialdehyde dehydrogenase; $\boldsymbol{c g m \boldsymbol { A }}$, cyclic beta-1,2-glucan modification protein; dapA (2 copies),

4-hydroxy-tetrahydrodipicolinate synthase; $\boldsymbol{d a p B}$ (2 copies), 4-hydroxy-tetrahydrodipicolinate reductase; $\boldsymbol{d} \boldsymbol{d \boldsymbol { h }}$ (2 copies), meso-diaminopimelate D-dehydrogenase; $\mathbf{g} \mathbf{a b D}$, succinate-semialdehyde dehydrogenase; $\mathbf{g a b T}, 4$-aminobutyrate aminotransferase; gapA, Glyceraldehyde-3-phosphate dehydrogenase A; $\boldsymbol{h o m}{ }^{V 59 A}$, reduced activity homoserine dehydrogenase; $\boldsymbol{I d} \boldsymbol{C} \boldsymbol{C}$, constitutive lysine decarboxylase; IdhA, D-lactate dehydrogenase; Iys $\boldsymbol{A}$ (2 copies), diaminopimelate decarboxylase; Iys $\mathbf{C}^{\mathbf{T} 311 /}$ (2 copies), high activity aspartokinase; IysE (2 copies), lysine exporter; $\mathbf{o d h A}^{\boldsymbol{T T G}}$, reduced activity 2-oxoglutarate dehydrogenase; $\mathbf{o d h l}^{\boldsymbol{T} \mathbf{1 5 A}}$, high activity oxoglutarate dehydrogenase inhibitor; patA, putrescine aminotransferase; $\boldsymbol{p a t} \boldsymbol{D}$, gamma-aminobutyraldehyde dehydrogenase; $\boldsymbol{p c k}$,

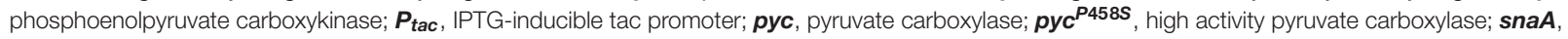
$\mathrm{N}$-acetyltransferase; $\boldsymbol{s p e} \boldsymbol{C}$, ornithine decarboxylase; $\boldsymbol{s u g} \boldsymbol{R}$, central transcriptional regulator of the carbon metabolism; $\boldsymbol{x y} \mathbf{I} \boldsymbol{A}_{\boldsymbol{X}}$, xylose isomerase from Xanthomonas

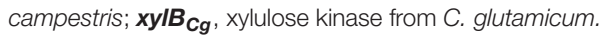

[OPA] (Agilent). Putrescine and 5-AVA were resolved with Zorbax Eclipse AAA column (Agilent) using $40 \mathrm{mM}$ sodium phosphate buffer (Agilent) and acetonitrile methanol-water in the ratio $(45: 45: 10)$ in a gradient elution program.

\section{Authentication of Putrescine Production From Xylose by Engineered C. glutamicum PUT Xyl}

Even though the 5-aminovalerate production from xylose by C. glutamicum AVA Xyl was already shown by Jorge et al. (2017b), the putrescine production from xylose by C. glutamicum PUT Xyl has to be confirmed. Therefore, a growth and production study using CGXII minimal medium was conducted and subsequent putrescine measurement via HPLC analysis was performed. Since a previous growth experiment showed a slow growth of PUT Xyl ( $\mu=0.05 \pm 0.003$ ) on xylose (data not shown), a control supplemented with minimum glucose of $0.5 \mathrm{~g} \mathrm{~L}^{-1}$ for supporting the initial growth rate was chosen. Growth was observed by measuring $\mathrm{OD}_{600}$, and samples for HPLC analysis were taken after 6,24 , and $72 \mathrm{~h}$ of cultivation.

\section{Simultaneous Utilization of Glucose and Xylose by the Engineered C. glutamicum Strains in CGXII Minimal Medium by Batch Fermentation}

For the production experiments, CGXII medium was formulated with different combinations of glucose and xylose making the total sugar concentration $40 \mathrm{~g} \mathrm{~L}^{-1}$ and a $\mathrm{pH}$ of 7 . Overnight cultures of the C. glutamicum strains in BHI medium were harvested by centrifugation at 5,000 rpm for $10 \mathrm{~min}$, washed in minimal medium without sugar and inoculated to the CGXII minimal medium with an initial optical density at $600 \mathrm{~nm}$ $\left(\mathrm{OD}_{600}\right)$ of 1.0. The growth of the cells was monitored by measuring the absorbance at $600 \mathrm{~nm}$ in a spectrophotometer (Tecan plate reader infinite 200 Pro, Switzerland). Samples were 
withdrawn at the desired interval of time and checked for sugar consumption and product formation as per standard protocols.

\section{Preparation of Rice Straw Hydrolysate (RSH)}

Rice straw procured from the local markets was used for the study. Dried rice straw milled into a particle size of $\leq 1 \mathrm{~mm}$ was subjected to alkali pretreatment with a solid loading of $20 \%(\mathrm{w} / \mathrm{w})$ and $\mathrm{NaOH}$ loading of $2 \%(\mathrm{w} / \mathrm{v})$, at $121^{\circ} \mathrm{C}$ for $1 \mathrm{~h}$. The pretreated biomass slurry was allowed to cool at room temperature, neutralized with $10 \mathrm{~N} \mathrm{H}_{2} \mathrm{SO}_{4}$, wet sieved and air-dried before enzymatic hydrolysis. Later, the wet sieved neutralized biomass was saccharified with commercial cellulase (Zytex India Limited, Mumbai) with an enzyme load of $20 \mathrm{FPUs} / \mathrm{g}$ of the substrate and a biomass loading of $10 \%(\mathrm{w} / \mathrm{w})$, at $50{ }^{\circ} \mathrm{C}$, $180 \mathrm{rpm}$ for $48 \mathrm{~h}$. A pH of 4.8 was maintained using citrate buffer $(0.5 \mathrm{M})$. The liquid fraction called the RSH was separated from the whole slurries by centrifugation and filter-sterilized using $0.22(47 \mathrm{~mm}) \mu \mathrm{m}$ filter membranes (Millipore, Massachusetts, United States) prior to fermentation.

\section{Utilization of RSH as a Sole Carbon Source by AVA Xyl and PUT Xyl}

To study the potential of utilizing low-value sugars in the agroresidual wastes by the Corynebacterium biocatalysts, shake flask batch fermentations were carried out at $30^{\circ} \mathrm{C}$ and $200 \mathrm{rpm}$. The production medium with $\mathrm{RSH}$ was formulated with $20 \mathrm{~g} \mathrm{~L}^{-1}$ $\left(\mathrm{NH}_{4}\right)_{2} \mathrm{SO}_{4}, 5 \mathrm{~g} \mathrm{~L}^{-1}$ Urea, $1 \mathrm{~g} \mathrm{~L}^{-1} \mathrm{~K}_{2} \mathrm{HPO}_{4}, 1 \mathrm{~g} \mathrm{~L}^{-1} \mathrm{KH}_{2} \mathrm{PO}_{4}$, $0.25 \mathrm{~g} \mathrm{~L}^{-1} \mathrm{MgSO}_{4}$. $7 \mathrm{H}_{2} \mathrm{O}, 42 \mathrm{~g} \mathrm{~L}^{-1} \mathrm{MOPS}, 0.02 \mathrm{mg} \mathrm{L}^{-1}$ biotin, $10 \mathrm{mg} \mathrm{L}^{-1} \mathrm{CaCl}_{2}$ and necessary trace elements in $\mathrm{RSH}$, adjusted to $\mathrm{pH} 7$ using $10 \mathrm{~N} \mathrm{NaOH}$. Overnight grown seed cultures in the BHI medium were inoculated to $\mathrm{RSH}$ based production medium $(100 \mathrm{~mL})$ to attain an initial OD of 1.0 and incubated at $30{ }^{\circ} \mathrm{C}$, in a rotary shaker $(200 \mathrm{rpm})$. The growth pattern of both strains was determined by a spectrophotometer. The sugar utilization and the production of the two recombinant strains were estimated by HPLC.
All the experiments were performed in triplicates and all the data were expressed as the mean \pm standard deviation of three independent replicates.

\section{RESULTS AND DISCUSSION}

\section{Validation of Biosynthesis of Putrescine by the Recombinant Strain PUT Xyl in CGXII Medium}

Unlike AVA Xyl, which was studied earlier for 5-AVA biosynthesis, as indicated in the methodology, initially we checked the xylose utilization potentiality of the new construct PUT Xyl for proof of the concept. As shown in Figure 2B, a lower putrescine production of $26.66 \pm 1.40 \mathrm{mg} \mathrm{L}^{-1}$ and a growth rate of $0.040 \pm 0.002 \mathrm{~h}^{-1}$ was observed after $72 \mathrm{~h}$, in the shake flask which initially contained $40 \mathrm{~g} \mathrm{~L}^{-1}$ of xylose alone as the carbon source. The growth was picked up to $0.137 \pm 0.008 \mathrm{~h}^{-1}$ (Figure 2A) when a minimal amount of glucose $\left(5 \mathrm{~g} \mathrm{~L}^{-1}\right)$ was supplemented initially along with xylose $\left(35 \mathrm{~g} \mathrm{~L}^{-1}\right)$ and the putrescine production titer increased to $97.88 \pm 2.07 \mathrm{mg} \mathrm{L}^{-1}$.

\section{Production of Putrescine and 5-AVA by PUT Xyl and AVA Xyl in CGXII Minimal Medium With the Simultaneous Utilization of Glucose and Xylose}

A detailed study was conducted with varying concentrations of glucose (5-40 $\left.\mathrm{g} \mathrm{L}^{-1}\right)$ and xylose (5-40 $\left.\mathrm{g} \mathrm{L}^{-1}\right)$, to analyze the efficacy of both AVA Xyl and PUT Xyl strains in co-utilizing pure glucose and xylose initially making a total sugar of $40 \mathrm{~g}$ $\mathrm{L}^{-1}$ in CGXII minimal medium. After $72 \mathrm{~h}$ of fermentation, $96.74 \pm 5.66 \mathrm{mg} \mathrm{L}^{-1}$ putrescine was obtained with a growth rate of $0.145 \pm 0.100 \mathrm{~h}^{-1}$, when the PUT Xyl strain fermented an equal amount of glucose $\left(20 \mathrm{~g} \mathrm{~L}^{-1}\right)$ and xylose $\left(20 \mathrm{~g} \mathrm{~L}^{-1}\right)$. The same 1:1 combination of sugars yielded $602.74 \pm 2.15 \mathrm{mg}$ $\mathrm{L}^{-1}$ 5-AVA after $72 \mathrm{~h}$ and a growth rate of $0.187 \pm 0.002 \mathrm{~h}^{-1}$
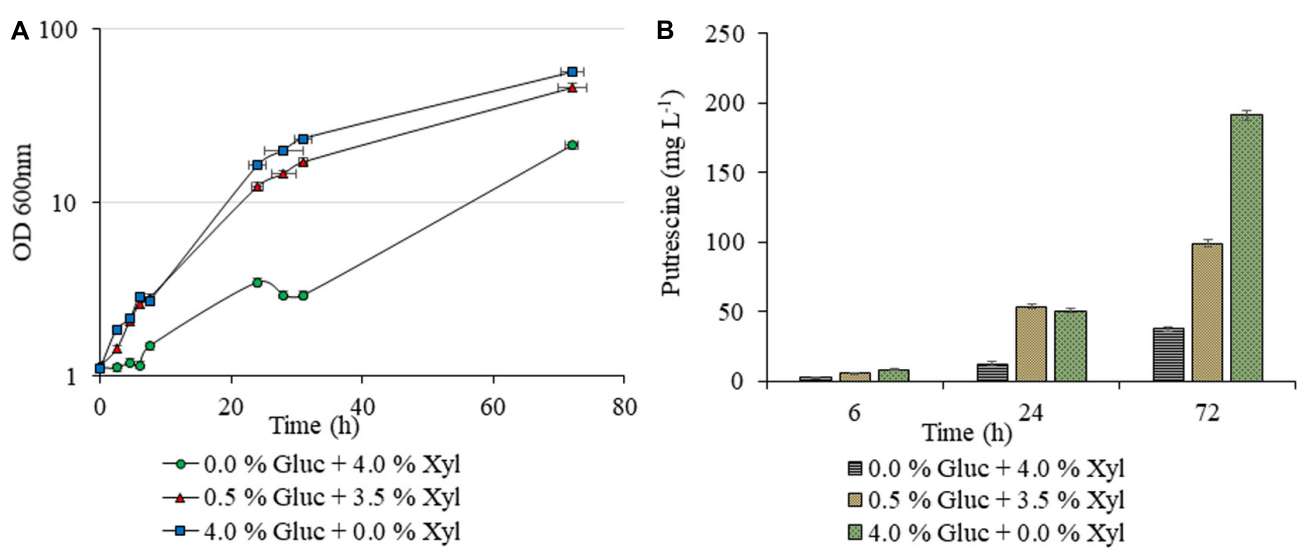

FIGURE 2 | Putrescine production of $C$. glutamicum PUT Xyl. Growth curves of $C$. glutamicum PUT Xyl cultivated in shake flasks of $20 \mathrm{~mL}$ CGXII minimal medium supplemented with different compositions of glucose (Gluc) and xylose (Xyl) (A), and putrescine concentrations measured after 0, 6, 24, and 72 h of cultivation (B). Measurements are given as means from triplicates of independent cultivations with standard deviation. 
when AVA Xyl strain was used. The utilization of xylose by the two recombinant strains, even in the presence of glucose shows their efficacy to co-metabolize the xylose and glucose present in the fermentation medium. The xylose consumption was evidently facilitated once the glucose pool reached a depletion. This metabolic shift from glucose to xylose suggests that the xylose machinery including the overexpressed $x y l A$ xylB genes is also active even in the presence of glucose. When the medium contained $25 \mathrm{~g} \mathrm{~L}^{-1}$ glucose and $15 \mathrm{~g} \mathrm{~L}^{-1}$ xylose, the entire glucose and $64.28 \pm 0.13 \%$ (Figure $3 \mathbf{A}$ ) of xylose was consumed by PUT Xyl, which is about $9.29 \pm 0.04 \mathrm{~g} \mathrm{~L}^{-1}$, at a rate of $0.152 \pm 0.004 \mathrm{~g} \mathrm{~L}^{-1} \mathrm{~h}^{-1}$ (Figure 3B) to produce $109.43 \pm 2.11 \mathrm{mg} \mathrm{L}^{-1}$ of putrescine (Figure 3C) after $72 \mathrm{~h}$ and grew faster $\left(\mu=0.148 \pm 0.060 \mathrm{~h}^{-1}\right)$. The percentage of xylose utilized by the AVA Xyl strain is shown in Figure 4A. Almost $9.10 \pm 0.05 \mathrm{~g} \mathrm{~L}^{-1}$ of xylose was uptaken by AVA Xyl at a rate of $0.198 \pm 0.012 \mathrm{~g} \mathrm{~L}^{-1} \mathrm{~h}^{-1}$ (Figure 4B), along with the whole glucose, grew at a rate of $0.188 \pm 0.005 \mathrm{~h}^{-1}$ and gave an AVA titer of $874.43 \pm 0.98 \mathrm{mg} \mathrm{L}^{-1}$ (Figure 4C) after $72 \mathrm{~h}$. The increase in the initial glucose concentration in the medium resulted in a slight decline of the xylose uptake which may be due to the repression offered by glucose.

A slight decrease in the production, of putrescine $\left(92.93 \pm 2.83 \mathrm{mg} \mathrm{L}^{-1}\right)$ and 5-AVA $\left(553.93 \pm 4.67 \mathrm{mg} \mathrm{L}^{-1}\right)$ as well as in the growth of PUT Xyl and AVA Xyl was observed with a combination of $15 \mathrm{~g} \mathrm{~L}^{-1}$ glucose and $25 \mathrm{~g} \mathrm{~L}^{-1}$ xylose. As mentioned in section "Validation of Biosynthesis of Putrescine by the Recombinant Strain PUT Xyl in CGXII Medium," the least putrescine $\left(26.66 \pm 1.40 \mathrm{mg} \mathrm{L}^{-} 1\right)$ and also 5-AVA production $\left(52.66 \pm 0.09 \mathrm{mg} \mathrm{L}^{-1}\right)$ was observed when xylose $\left(40 \mathrm{~g} \mathrm{~L}^{-1}\right)$ alone was the only sugar source. Though the highest amounts of putrescine of about $195.71 \pm 0.69 \mathrm{mg} \mathrm{L}^{-1}$ and 5-AVA of $1508.71 \pm 3.21 \mathrm{mg} \mathrm{L}^{-1}$ were obtained in the shake flask with $40 \mathrm{~g} \mathrm{~L}^{-1}$ glucose, significant productions were observed when glucose is partially replaced with different ratios of xylose. The comparable production titer of the respective compounds when a mixture of glucose and xylose was used, revealed that both the recombinant strains were capable of co utilizing them to produce respective products, the putrescine and 5-AVA.

\section{Exploitation of the Fermentable Sugars in the RSH for the Production of Putrescine and 5-AVA}

The efficacy of PUT Xyl and AVA Xyl strains to ferment the saccharified sugars in the lignocellulosic hydrolysate was evaluated after validating the proof of concept in the CGXII synthetic medium. The RSH after $48 \mathrm{~h}$ of hydrolysis contained glucose (23.76 $\mathrm{g} \mathrm{L}^{-1}$ ) and xylose (12.65 $\mathrm{g} \mathrm{L}^{-1}$ ) (Figure 5A) and the formulated RSH based production medium had a total sugar (mainly glucose and xylose) of $3.64 \%$. The sugar utilization, growth and production by PUT Xyl and AVA Xyl in the RSH based medium containing $\left(23.7 \mathrm{~g} \mathrm{~L}^{-1}\right.$ glucose $+12.6 \mathrm{~g} \mathrm{~L}^{-1}$ xylose) was comparable to that in the CGXII medium, with the most proximate sugar concentration $\left(25 \mathrm{~g} \mathrm{~L}^{-1}\right.$ glucose and $15 \mathrm{~g} \mathrm{~L}^{-1}$ xylose). However, engineered C. glutamicum strains when cultivated in the RSH based medium had a longer lag phase. After $24 \mathrm{~h}$, the PUT Xyl strain attained a growth rate of
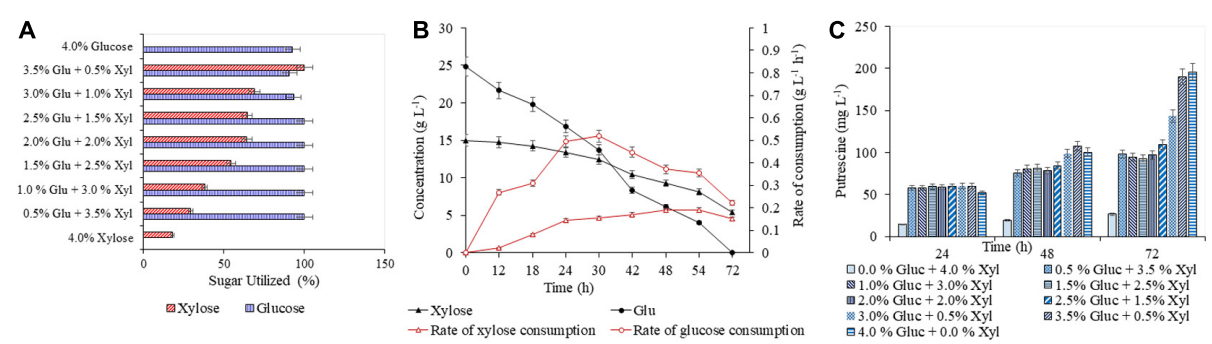

FIGURE 3 | Production of putrescine in CGXII synthetic medium with different blends of glucose and xylose. The percentage utilization of glucose and xylose by PUT $\mathrm{Xyl}$ is shown in (A). The glucose and xylose consumption rate of PUT Xyl is shown in (B). The time profile of the putrescine production is shown in (C).

Measurements are given as means from triplicates of independent cultivations with standard deviation.
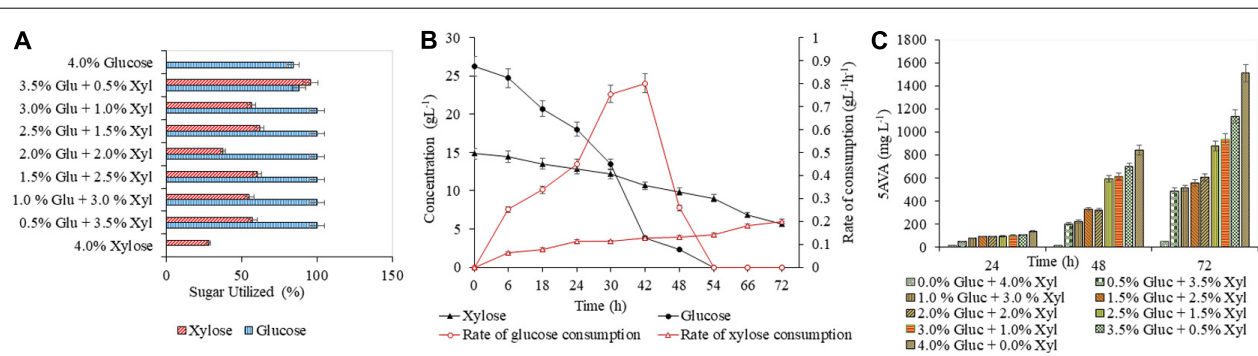

FIGURE 4 | Production of 5-AVA in CGXII medium with different blends of glucose and xylose. The utilization of glucose and xylose by PUT Xyl is shown in (A). The glucose and xylose consumption rate of AVA Xyl is shown in (B). The time profile of the 5-AVA production is shown in (C). Measurements are given as means from triplicates of independent cultivations with standard deviation. 

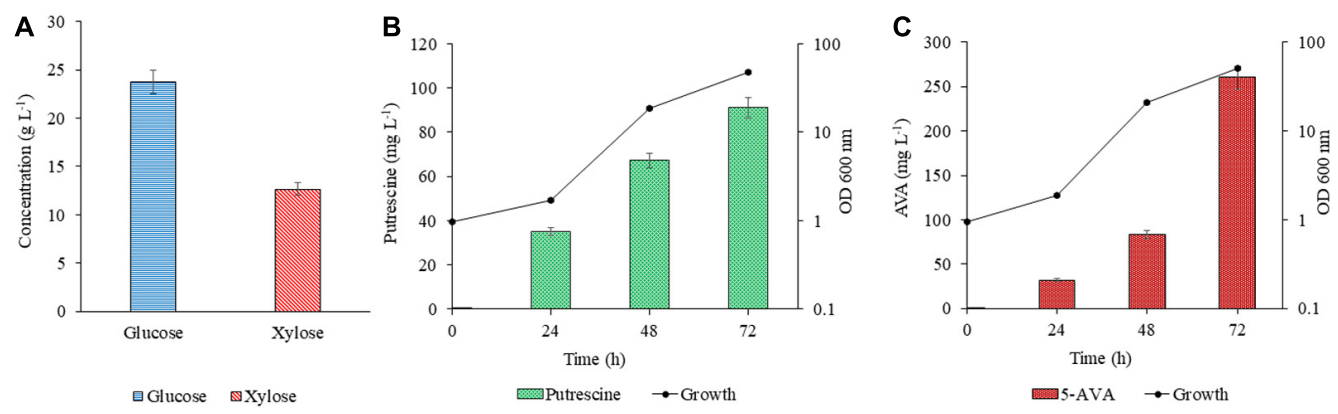

FIGURE 5 | Concentration of glucose and xylose in RSH (A). Production of putrescine (B) and 5 AVA (C) from RSH. Hydrolysate contained $2.37 \mathrm{~g} \mathrm{~L}^{-1}$ glucose $+12.6 \mathrm{~g} \mathrm{~L}^{-1}$ xylose. The downward diagonal column represents the production and the line graph with marker shows the absorbance at OD $600 \mathrm{~nm}$. Measurements are given as means from triplicates of independent cultivations with standard deviation.

$0.013 \pm 0.004 \mathrm{~h}^{-1}$, whereas the AVA Xyl strain had a growth rate of $0.003 \pm 0.001 \mathrm{~h}^{-1}$. Thereafter, the growth was picked up to $0.130 \pm 0.028 \mathrm{~h}^{-1}$ and $0.140 \pm 0.031 \mathrm{~h}^{-1}$ by PUT Xyl and AVA $\mathrm{Xyl}$, respectively, and the xylose and glucose in the RSH were fermented to yield $91.00 \pm 2.58 \mathrm{mg} \mathrm{L}^{-1}$ putrescine (Figure $5 \mathrm{~B}$ ) and $260.33 \pm 2.47 \mathrm{mg} \mathrm{L}^{-1} 5$-AVA (Figure 5C) after $72 \mathrm{~h}$.

Polyamide (PA), commonly known as nylon, is a polymer with a myriad of pharmaceutical and industrial applications and is currently synthesized by petrochemical routes. Chemically, the polymer backbone is composed of repetitive units of diamines and dicarboxylic acids that contain different numbers of carbon atoms, imparting a variety of material properties. Globally, the demand for polyamides has fairly increased and is expected to grow at a CAGR of $7.1 \%$ in a forecast period of 2020-2027. The petroleum-based fossil fuels remarkably contribute to $60 \%$ of one-fifth of the $\mathrm{CO}_{2}$ emission because nearly $82 \%$ of the global energy needs are met by non-renewable energy sources such as petroleum, coal and natural gas (Gupta and Verma, 2015).

Biomass has been considered to be the only sustainable source of organic carbon on earth and the net-zero carbon emission makes it the best analogy to petroleum for the production of value-added chemicals (Sharma et al., 2019). Howbeit we have employed the plasmid-based expression, a genome-based expression for the amplification of the $x y l A$ and $x y l B$, genes are preferred over the plasmid-based expression system to avert its instability problems for industrial-scale applications. In the current study, we have focused on the bacterial synthesis of a diamine and a dicarboxylic acid by exploiting the lowvalue sugars in the lignocellulosic biomass-rice straw, using the engineered C. glutamicum strains capable of consuming xylose and glucose. This was established by genetically modifying the metabolic pathways in C. glutamicum and make it a selfsufficient host for the utilization of the C5 sugar xylose, a fair amount of which is gone underutilized in the form of agro-residues. Since the wild type C. glutamicum deficient of the xylose isomerase activity is unable to utilize xylose neither in aerobic nor in oxygen-deprived conditions (Kawaguchi et al., 2006) here in this study, we have further modified the NA6 strain, previously reported by Nguyen et al. (2015), for xylose utilization and its biotransformation to putrescine.
Meiswinkel et al. (2013) studied the growth of C. glutamicum strains harboring different $x y l A$ and $x y l B$ genes from $B$. subtilis, E. coli, $M$. smegmatis, and $X$. campestris and reported that the recombinant strains with heterologous expression of the endogenous $x y l B$ gene from $C$. glutamicum in addition to the xylA gene from $X$. campestris improved xylose utilization and grew well $\left(\mu=0.199 \pm 0.009 \mathrm{~h}^{-1}\right)$ in CGXII medium with xylose as the sole carbon source. The toxicity of putrescine to any microorganisms (Incorvia, 2015) was believed to be a hindrance for the active exploration of bacterial putrescine production (Qian et al., 2009) but C. glutamicum can tolerate higher concentrations ( $44 \mathrm{~g} \mathrm{~L}^{-1}$ ) of putrescine (Schneider and Wendisch, 2010; Jorge et al., 2017a). An E. coli strain XQ52 harboring p15SpeC was reported to produce $21.7 \mathrm{~g} \mathrm{~L}^{-1}$ in $32 \mathrm{~h}$, by the consumption of glucose via fed-batch fermentation (Noh et al., 2017). In our study, the putrescine titer obtained using the engineered C. glutamicum strain PUT Xyl was $109.43 \pm 2.11 \mathrm{mg}$ $\mathrm{L}^{-1}$ in the shake flasks with CGXII containing $25 \mathrm{~g} \mathrm{~L}^{-1}$ glucose and $15 \mathrm{~g} \mathrm{~L}^{-1}$ xylose.

The collection of raw material, its availability throughout the seasons, transportation and storage are the major difficulties in any study related to the agro residual biomass. The digestibility of cellulose present in lignocellulosic biomass is hindered by many physicochemical, structural, and compositional factors are one of the major concerns. The biomass needs to be treated so that the cellulose in the plant fibers is exposed. The goal of the pretreatment process is to break down the lignin structure and disrupt the crystalline structure of cellulose so that the enzymes can easily access and hydrolyze the cellulose. The alkali pretreatment decreases the lignin by about $47 \%$ and increases the glucan by about $50 \%$ (Oberoi et al., 2012). The enzymatic hydrolysis of the alkali pretreated rice straw had a fair glucose $\left(23.7 \mathrm{~g} \mathrm{~L}^{-1}\right)$ and xylose $\left(12.6 \mathrm{~g} \mathrm{~L}^{-1}\right)$ composition, which were fermented to value-added chemicals such as 5-AVA $\left(260.33 \pm 2.47 \mathrm{mg} \mathrm{L}^{-1}\right)$ and putrescine $\left(91.00 \pm 2.58 \mathrm{mg} \mathrm{L}^{-1}\right)$ by AVA Xyl and PUT Xyl. The recombinant C. glutamicum strains overexpressing the transformed $x y l A, x y l B$ genes were proved efficient to uptake the fermentable sugars from $\mathrm{RSH}$ based medium and biosynthesize the compounds of interest. The recombinant C. glutamicum strains co-utilize the xylose along 
with glucose present in the lignocellulosic hydrolysates but the presence of pre-treatment derived inhibitors like furfural and/or hydroxyl methyl furfural attributes to the slower growth and production when hydrolysate based media is used (Gopinath et al., 2011). In this study, we have observed the utilization of both glucose and xylose by the modified C. glutamicum strains in the CGXII medium and as well as in the RSH based medium. A higher titer of 5-AVA (39.93 $\mathrm{g} \mathrm{L}^{-1}$ ) than from the glucose fermentation was obtained in Miscanthus hydrolysate solution by fed-batch fermentation employing the recombinant C. glutamicum KCTC 1857 expressing the $\operatorname{davBA}$ genes (Joo et al., 2017). Industrial sugar beet thick juice was reported as a suitable carbon source for Corynebacterium and produced putrescine with a volumetric productivity of $0.28 \pm 0.01 \mathrm{~g} \mathrm{~L}^{-1} \mathrm{~h}^{-1}$ (Meiswinkel et al., 2014). In our study, C. glutamicum PUT Xyl produced putrescine from the rice straw hydrolysate-based medium with a volumetric productivity of $1.26 \pm 0.31 \mathrm{mg} \mathrm{L}^{-1} \mathrm{~h}^{-1}$. A study by Nguyen and Lee (2019), represented the bioconversion of methane to putrescine using an engineered Methylomicrobium alcaliphilum 20ZE4-pACO strain with a putrescine titer of $98.08 \mathrm{mg} \mathrm{L}^{-1}$. A lower growth rate was observed in RSH based medium when compared to the most proximate sugar concentration of that in the CGXII minimal medium for both the strains, which may be due to the hindrances offered by the pre-treatment derived inhibitors (Gopinath et al., 2011).

\section{CONCLUSION}

The ability for the simultaneous utilization of glucose and the pentose sugar xylose by the two engineered C. glutamicum strains AVA Xyl and PUT Xyl to produce 5-AVA and putrescine opened up a new avenue to utilize them for the production of such value-added products from renewable sources such as lignocellulosic biomass which generally goes as a surplus waste product in the agricultural sector. The tolerance of C. glutamicum to grow in pretreated biomass hydrolysate is yet another added advantage of this wonderful industrial strain making them an excellent biocatalyst in biorefineries for improving the techno-economic feasibility of the entire processes. As of now, we could demonstrate the production of value-added wide spectrum products such as lysine, xylitol, xylonic acid, etc., from biomass using carefully drafted and engineered C. glutamicum strains. Here we have demonstrated a green bioprocess for

\section{REFERENCES}

Adkins, J., Jordan, J., and Nielsen, D. R. (2013). Engineering Escherichia coli for renewable production of the 5-carbon polyamide building-blocks 5aminovalerate and glutarate. Biotechnol. Bioeng. 110, 1726-1734. doi: 10.1002/ bit. 24828

Binod, P., Sindhu, R., Singhania, R. R., Vikram, S., Devi, L., Nagalakshmi, S., et al. (2010). Bioethanol production from rice straw: an overview. Bioresour. Technol. 101, 4767-4774. doi: 10.1016/j.biortech.2009. 10.079

Cho, J. S., Jeong, K. J., Choi, J. W., Park, S. H., Joo, J. C., Park, S. J., et al. (2016). Metabolic engineering of Corynebacterium glutamicum for enhanced production of 5-aminovaleric acid. Microb. Cell Fact. 15, 1-13. the production of two highly demanded building blocks of the polyamide industry such as 5AVA and putrescine from a renewable raw material like rice straw. Process strategies employing synthetic, mutually dependent consortia (Sgobba et al., 2018) or dynamically controlled co-cultivation of two recombinant C. glutamicum strains (Pérez-Garcia et al., 2021) may be used for further optimization. Successful upscaling of the process can be a breakthrough in white biotechnology for the production of bioplastics.

\section{DATA AVAILABILITY STATEMENT}

The raw data supporting the conclusions of this article will be made available by the authors, without undue reservation.

\section{AUTHOR CONTRIBUTIONS}

KN and VW acquired funding and designed the study. KS carried out the biomass pretreatment, shake flask fermentation, and production data analysis. SH and VW constructed the production strains as part of the Indo German collaboration work. SH wrote the manuscript portions pertaining to the strain construction details. KS and KN designed and drafted the final manuscript. VW did the critical reading. All authors read and approved the final manuscript.

\section{FUNDING}

This study was supported by the grant from the Indo-German DBT BMBF project BIOCON.

\section{ACKNOWLEDGMENTS}

We would like to thank the DBT, New Delhi and BMBF, Germany for financial support.

\section{SUPPLEMENTARY MATERIAL}

The Supplementary Material for this article can be found online at: https://www.frontiersin.org/articles/10.3389/fbioe. 2021.635509/full\#supplementary-material

Duff, S. J. B., and Murray, W. D. (1996). Bioconversion of forest products industry waste cellulosics to fuel ethanol: a review. Bioresour. Technol. 55, 1-33. doi: 10.1016/0960-8524(95)00122-0

Eggeling, L., and Bott, M. (eds). (2005). Handbook of Corynebacterium glutamicum, 1st Edn, FL, United States: CRC Press. doi: 10.1201/9781420039696

Gopinath, V., Meiswinkel, T. M., Wendisch, V. F., and Nampoothiri, K. M. (2011). Amino acid production from rice straw and wheat bran hydrolysates by recombinant pentose-utilizing Corynebacterium glutamicum. Appl. Microbiol. Biotechnol. 92, 985-996. doi: 10.1007/s00253-011-3478-x

Grand View Research Inc (2020). High Performance Polyamides Market Size, Share \& Trends Analysis Report By Type (PA 6T, Polyarylamide, PA 12, PA 9T, PA 11, PA 46, Polyphthalamides), By End-use Industry, By Region, And Segment Forecasts, 2020 - 2027. GVR-4-68038-813-8, R. id. 
Gupta, A., and Verma, J. P. (2015). Sustainable bio-ethanol production from agroresidues: a review. Renew. Sustain. Energy Rev. 41, 550-567. doi: 10.1016/j.rser. 2014.08.032

Incorvia, C. (2015). (??) United States Patent, Vol. 2. 3131-3135.

Jae, S., Young, E., Noh, W., Min, H., Hoon, Y., Hwan, S., et al. (2013). Metabolic engineering of Escherichia coli for the production of 5-aminovalerate and glutarate as C5 platform chemicals. Metab. Eng. 16, 42-47. doi: 10.1016/j. ymben.2012.11.011

Joo, J. C., Oh, Y. H., Yu, J. H., Hyun, S. M., Khang, T. U., Kang, K. H., et al. (2017). Production of 5-aminovaleric acid in recombinant Corynebacterium glutamicum strains from a Miscanthus hydrolysate solution prepared by a newly developed Miscanthus hydrolysis process. Bioresour. Technol. 245, 1692-1700. doi: 10.1016/j.biortech.2017.05.131

Jorge, J. M. P., Leggewie, C., and Wendisch, V. F. (2016). A new metabolic route for the production of gamma-aminobutyric acid by Corynebacterium glutamicum from glucose. Amino Acids 48, 2519-2531. doi: 10.1007/s00726-016-2272-6

Jorge, J. M. P., Nguyen, A. Q. D., Pérez-García, F., Kind, S., and Wendisch, V. F. (2017a). Improved fermentative production of gamma-aminobutyric acid via the putrescine route: systems metabolic engineering for production from glucose, amino sugars, and xylose. Biotechnol. Bioeng. 114, 862-873. doi: 10. 1002/bit.26211

Jorge, J. M. P., Pérez-García, F., and Wendisch, V. F. (2017b). A new metabolic route for the fermentative production of 5-aminovalerate from glucose and alternative carbon sources. Bioresour. Technol. 245, 1701-1709. doi: 10.1016/ j.biortech.2017.04.108

Kawaguchi, H., Sasaki, M., Vertès, A. A., Inui, M., and Yukawa, H. (2006). Engineering of a xylose metabolic pathway in Corynebacterium glutamicum. Appl. Microbiol. Biotechnol. 77, 1053-1062. doi: 10.1007/s00253-007-1244-x

Kim, S., and Dale, B. E. (2004). Global potential bioethanol production from wasted crops and crop residues. Biomass Bioenergy 26, 361-375. doi: 10.1016/j. biombioe.2003.08.002

Kirchner, O., and Tauch, A. (2003). Tools for genetic engineering in the amino acidproducing bacterium Corynebacterium glutamicum. J. Biotechnol. 104, 287-299. doi: 10.1016/S0168-1656(03)00148-2

Krause, F. S., Blombach, B., and Eikmanns, B. J. (2010). Metabolic engineering of Corynebacterium glutamicum for 2-Ketoisovalerate production. Appl. Environ. Microbiol. 76, 8053-8061. doi: 10.1128/AEM.01710-10

Liu, P., Zhang, H., Lv, M., Hu, M., Li, Z., Gao, C., et al. (2014). Enzymatic production of 5-aminovalerate from L-lysine using L-lysine monooxygenase and 5-aminovaleramide amidohydrolase. Sci. Rep. 4:5657. doi: 10.1038/ srep05657

Meiswinkel, T., Lindner, S., and Wendisch, V. F. (2014). Thick juice-based production of amino acids and putrescine by Corynebacterium glutamicum. J. Biotechnol. Biomater. 4:167. doi: 10.4172/2155-952x.1000167

Meiswinkel, T. M., Gopinath, V., Lindner, S. N., Nampoothiri, K. M., and Wendisch, V. F. (2013). Accelerated pentose utilization by Corynebacterium glutamicum for accelerated production of lysine, glutamate, ornithine and putrescine. Microb. Biotechnol. 6, 131-140. doi: 10.1111/1751-7915.12001

Mindt, M., Hannibal, S., Heuser, M., Risse, J. M., Sasikumar, K., Nampoothiri, M., et al. (2019). Fermentative production of $\mathrm{N}$-alkylated glycine derivatives by recombinant Corynebacterium glutamicum using a mutant of imine reductase DpkA from Pseudomonas putida. Front. Bioeng. Biotechnol. 7:232. doi: 10.3389/ fbioe.2019.00232

Mosier, N., Wyman, C., Dale, B., Elander, R., Lee, Y. Y., Holtzapple, M., et al. (2005). Features of promising technologies for pretreatment of lignocellulosic biomass. Bioresour. Technol. 96, 673-686. doi: 10.1016/j.biortech.2004.06.025

Nguyen, A. Q. D., Schneider, J., Reddy, G. K., and Wendisch, V. F. (2015). Fermentative production of the diamine Putrescine: system metabolic engineering of Corynebacterium glutamicum. Metabolites 5, 211-231. doi: 10. 3390/metabo5020211

Nguyen, L. T., and Lee, E. Y. (2019). Biological conversion of methane to putrescine using genome-scale model-guided metabolic engineering of a methanotrophic bacterium Methylomicrobium alcaliphilum 20Z. Biotechnol. Biofuels 12, 1-12. doi: 10.1186/s13068-019-1490-Z

Noh, M., Yoo, S. M., Kim, W. J., and Lee, S. Y. (2017). Gene expression knockdown by modulating synthetic small RNA Expression in Escherichia coli. Cell Syst. 5, 418-426.e4. doi: 10.1016/j.cels.2017.08.016

Oberoi, H. S., Babbar, N., Sandhu, S. K., Dhaliwal, S. S., Kaur, U., Chadha, B. S., et al. (2012). Ethanol production from alkali-treated rice straw via simultaneous saccharification and fermentation using newly isolated thermotolerant Pichia kudriavzevii HOP-1. J. Ind. Microbiol. Biotechnol. 39, 557-566. doi: 10.1007/ s10295-011-1060-2

Oberoi, H. S., Vadlani, P. V., Brijwani, K., Bhargav, V. K., and Patil, R. T. (2010). Enhanced ethanol production via fermentation of rice straw with hydrolysateadapted Candida tropicalis ATCC 13803. Process Biochem. 45, 1299-1306. doi: 10.1016/j.procbio.2010.04.017

Pérez-Garcia, F., Burgardt, A., Kallman, D. R., Wendisch, V. F., and Bar, N. (2021). Dynamic co-cultivation process of Corynebacterium glutamicum strains for the fermentative production of riboflavin. Fermentation 7:11. doi: 10.3390/ fermentation7010011

Peters-Wendisch, P. G., Schiel, B., Wendisch, V. F., Katsoulidis, E., Möckel, B., Sahm, H., et al. (2001). Pyruvate carboxylase is a major bottleneck for glutamate and lysine production by Corynebacterium glutamicum. J. Mol. Microbiol. Biotechnol. 3, 295-300.

Pukin, A. V., Boeriu, C. G., Scott, E. L., Sanders, J. P. M., and Franssen, M. C. R. (2010). An efficient enzymatic synthesis of 5-aminovaleric acid. J. Mol. Catal. B Enzym. 65, 58-62. doi: 10.1016/j.molcatb.2009.12.006

Qian, Z. G., Xia, X. X., and Lee, S. Y. (2009). Metabolic engineering of Escherichia coli for the production of putrescine: a four carbon diamine. Biotechnol. Bioeng. 104, 651-662. doi: 10.1002/bit.22502

Rey, D. A., Nentwich, S. S., Koch, D. J., Rückert, C., Pühler, A., Tauch, A., et al. (2005). The McbR repressor modulated by the effector substance Sadenosylhomocysteine controls directly the transcription of a regulon involved in sulphur metabolism of Corynebacterium glutamicum ATCC 13032. Mol. Microbiol. 56, 871-887. doi: 10.1111/j.1365-2958.2005.04586.x

Sarkar, N., Ghosh, S. K., Bannerjee, S., and Aikat, K. (2012). Bioethanol production from agricultural wastes: an overview. Renew. Energy 37, 19-27.

Sasaki, M., Jojima, T., Kawaguchi, H., Inui, M., and Yukawa, H. (2009). Engineering of pentose transport in Corynebacterium glutamicum to improve simultaneous utilization of mixed sugars. Appl. Microbiol. Biotechnol. 85, 105-115. doi: 10. 1007/s00253-009-2065-x

Schneider, J., Eberhardt, D., and Wendisch, V. F. (2012). Improving putrescine production by Corynebacterium glutamicum by fine-tuning ornithine transcarbamoylase activity using a plasmid addiction system. Appl. Microbiol. Biotechnol. 95, 169-178. doi: 10.1007/s00253-012-3956-9

Schneider, J., and Wendisch, V. F. (2010). Putrescine production by engineered Corynebacterium glutamicum. Appl. Microbiol. Biotechnol. 88, 859-868.

Sgobba, E., Stumpf, A. K., Vortmann, M., Jagmann, N., Dirks-hofmeister, M., Moerschbacher, B., et al. (2018). Synthetic Escherichia coli-Corynebacterium glutamicum consortia for 1-lysine production from starch and sucrose. Bioresour. Technol. 260, 302-310. doi: 10.1016/j.biortech.2018.03.113

Sharma, M., Singh, J., Baskar, C., and Kumar, A. (2019). A comprehensive review of renewable energy production from biomass-derived bio-oil. Biotechnologia 100, 179-194. doi: 10.5114/bta.2019.85323

Unthan, S., Baumgart, M., Radek, A., Herbst, M., Siebert, D., Brühl, N., et al. (2015). Chassis organism from Corynebacterium glutamicum - a top-down approach to identify and delete irrelevant gene clusters. Biotechnol. J. 10, 290-301. doi: 10.1002/biot.201400041

Veldmann, K. H., Minges, H., Sewald, N., Lee, J. H., and Wendisch, V. F. (2019). Metabolic engineering of Corynebacterium glutamicum for the fermentative production of halogenated tryptophan. J. Biotechnol. 291, 7-16. doi: 10.1016/ j.jbiotec.2018.12.008

Wendisch, V. F. (2003). Genome-wide expression analysis in Corynebacterium glutamicum using DNA microarrays. J. Biotechnol. 104, 273-285. doi: 10.1016/ S0168-1656(03)00147-0

Wieschalka, S., Blombach, B., and Eikmanns, B. J. (2012). Engineering Corynebacterium glutamicum for the production of pyruvate. Appl. Microbiol. Biotechnol. 94, 449-459. doi: 10.1007/s00253-011-3843-9

Conflict of Interest: The authors declare that the research was conducted in the absence of any commercial or financial relationships that could be construed as a potential conflict of interest.

Copyright (C) 2021 Sasikumar, Hannibal, Wendisch and Nampoothiri. This is an open-access article distributed under the terms of the Creative Commons Attribution License (CC BY). The use, distribution or reproduction in other forums is permitted, provided the original author(s) and the copyright owner(s) are credited and that the original publication in this journal is cited, in accordance with accepted academic practice. No use, distribution or reproduction is permitted which does not comply with these terms. 